\title{
Antimicrobial usage in cattle and poultry production in Dar es Salaam, Tanzania: pattern and quantity
}

Rogers Azabo 1,2,3* , Stephen Mshana ${ }^{4}$, Mecky Matee ${ }^{3,5}$ and Sharadhuli I. Kimera 3,6

\begin{abstract}
Background: Antimicrobials are extensively used in cattle and poultry production in Tanzania. However, there is dearth of information on its quantitative use. A questionnaire-based cross-sectional study was conducted from August to September 2019 in randomly selected poultry and small-scale dairy farms, in three districts of Dar es Salaam City eastern, Tanzania, to assess the practice and quantify antimicrobial use. Descriptive and statistical analyses were performed at a confidence interval of 95\%. The ratio of Used Daily Dose (UDD) and Defined Daily Dose (DDD) were used to determine whether the antimicrobial was overdosed or under dosed.

Results: A total of 51 poultry and 65 small-scale dairy farms were involved in the study. The route of antimicrobial administration was $98 \%$ orally via drinking water and $2 \%$ in feeds for poultry and for small-scale dairy farms, all through parenteral route. Seventeen types of antimicrobials comprising seven classes were recorded in poultry farms while nine belonging to six classes in the small dairy farms. Majority of the farms (poultry, $87.7 \%$ and small scale dairy, 84.3\%) used antimicrobials for therapeutic purposes. About $41 \%$ of the poultry and one third (34\%) of the dairy farmers' were not compliant to the drug withdrawal periods. Beta-lactams, fluoroquinolones, sulphonamides, tetracyclines and macrolides were the commonly used antimicrobials on these farms. In the poultry farms both those with records and those which relied on recall, antimicrobials were overdosed whereas in the small dairy farms, sulfadimidine, oxytetracycline and neomycin were within the appropriate dosing range (0.8-1.2). The majority (58.6\%) of farmers had adequate level of practices (favorable) regarding antimicrobial use in cattle and poultry production. This was associated with the age and level of education of the cattle and poultry farmers.

Conclusion: The study revealed a widespread misuse of antimicrobials of different types and classes in both poultry and small-scale dairy farming in Dar es Salaam, Tanzania. This result gives insight into the antimicrobial use practices and its quantification. The information obtained can guide and promote prudent use of antimicrobials among the farmers by developing mitigate strategies that reduce antimicrobial resistance risk potentials.
\end{abstract}

Keywords: Antimicrobial use, Cattle, Dar Es Salaam, Poultry, Practices, Quantity, Tanzania

*Correspondence: rogersazabo@gmail.com

${ }^{3}$ SACIDS Foundation for One Health Sokoine University of Agriculture,

Morogoro, Tanzania

Full list of author information is available at the end of the article

\section{Background}

Antimicrobial use in food animals has become an issue of global concern [1] due to its association with emergence of antimicrobial resistance (AMR) pathogens [2]. In Tanzania like any other low-middle income country, antimicrobial usage in animal production is weakly regulated and restricted [3].This has contributed to injudicious use of antimicrobials leading to the emergence and spread 
of resistance $[4,5]$. There is also evidence that lack of basic knowledge on the concept of AMR among livestock keepers may exacerbate the problem [6].

The increased antimicrobial usage in agriculture is driven by intensification in livestock production and demands for animal products [7]. Several studies have indicated indiscriminate use of antimicrobials in these livestock species [3, 8-10], fuelled by access without veterinarian prescription and expansion of the antimicrobial drug trade [6] to include non-therapeutic purposes [11]. The most commonly used antimicrobials in livestock production among the rural population in northern Tanzania are tetracyclines, pencillins, aminoglycosides, macrolides, and sulphonamides [2].

Despite the numerous studies on antimicrobial use in livestock [2-10], there is dearth of information on its practice and quantification in poultry and dairy cattle production in Tanzania especially in peri-urban / urban population Therefore, understanding the Antimicrobial use (AMU) practices of producers and precisely quantifying exposure to antimicrobials is critical for the success of interventions to improve AMU in cattle and poultry production.

The aim of this study is to assess farmers' antimicrobial use practices and quantification of antimicrobials used in poultry and small-scale dairy farms in Dar es Salaam, Tanzania. The findings of this study are likely to increase awareness of both "irrational" and "rational" uses of antimicrobials in food producing animals and also provide evidence based information to policy makers.

\section{Results}

\section{Farmers' socio-demographic characteristics}

The respondents in this study had a mean age of $54.5 \pm 12.1$ SD years and a majority $(28.4 \%)$ were in the age group (57-66) years (Fig.1). Most of the respondents interviewed were male (60\%), especially in the dairy farmer group (65\%). With regard to education (35.3\%) had achieved tertiary education level, $29.3 \%$ had secondary education, (33\%) primary education and $3(2.6 \%)$ not educated.

About $71 \%$ of the farmers indicated that livestock production was their main occupation. In addition, $62 \%$ of farmers had over 6 years of livestock rearing or management experience (Table 1 ).

\section{Practices of antimicrobial usage in cattle and poultry}

In this study, 23 (19.8\%) of the farms visited had antimicrobial use records while 93 (80.2) relied on recall (Additional file 1, Tables $1 \& 3$ ). In poultry production, $14(27.5 \%)$ of the farms had antimicrobial use records while $37(72.5 \%)$ farms relied on recall. Meanwhile in cattle production, $9(13.8 \%)$ of the farms had antimicrobial use records while $56(86.2 \%)$ relied on recall. However, in both scenarios the farmers had empty and newly used antimicrobial bottles and sachets. In cases where information was not sufficient online summary characteristic of the product was accessed.

There was no significant difference between the two antimicrobial data collection methods (records vs recall) and the Defined Daily Dose (DDD) at a probability cutoff of 0.05 .

\section{Qualitative antimicrobial use estimate}

Of the 116 farms visited 65 (56\%) were small-scale dairy farms while $51(44 \%)$ poultry farms and all of them used antimicrobials. On personnel that provided farmers with information on drug source, $82.8 \%(95 \% \mathrm{CI}, 74.9$, 88.6) mentioned veterinarians, including $83.1 \%$ of the dairy and $82.4 \%$ of poultry farmers while $3.4 \%$ reported

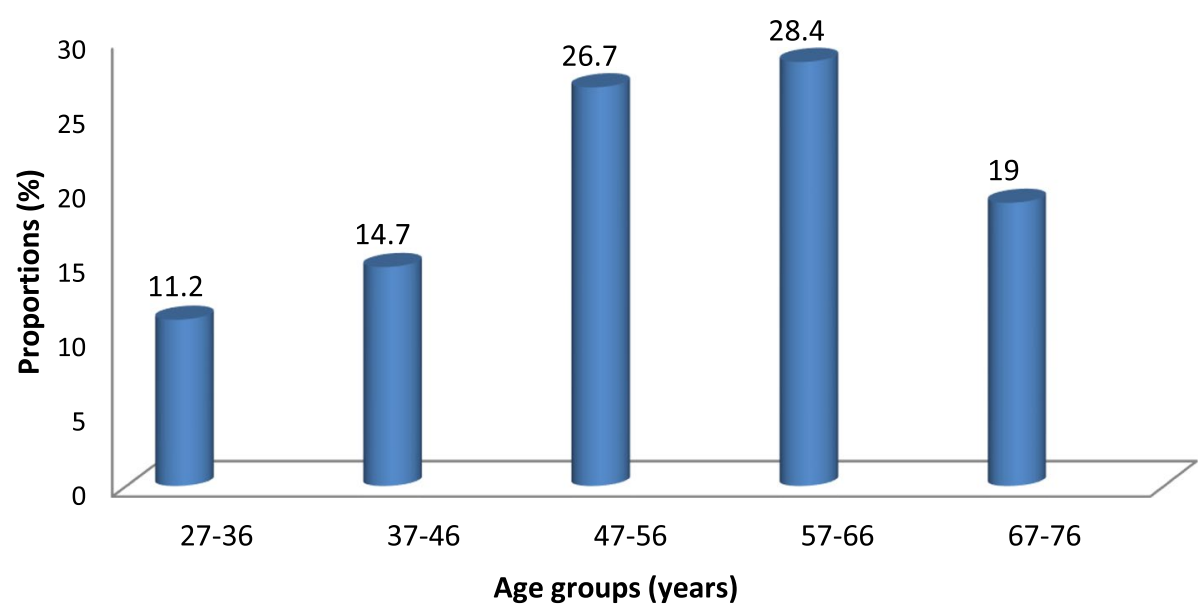

Fig. 1 Proportion of age distribution of cattle and poultry farmers in Dar-es-Salaam, Tanzania 
Table 1 Farmers' socio-demographic characteristics in Dar es Salaam, Tanzania

\begin{tabular}{|c|c|c|c|c|}
\hline \multirow[t]{2}{*}{ Variable } & \multicolumn{3}{|c|}{ Number of farmer categories, $n(\%)$} & \multirow[b]{2}{*}{$\begin{array}{l}\text { Confidence } \\
\text { interval } \\
(95 \%)\end{array}$} \\
\hline & Cattle (65) & Poultry (51) & Overall (116) & \\
\hline \multicolumn{5}{|l|}{ Gender } \\
\hline M & $42(64.6)$ & $27(52.9)$ & $69(59.5)$ & $50.4,67.9$ \\
\hline $\mathrm{F}$ & 23(35.4) & $24(47.1)$ & $47(40.5)$ & $32.0,49.6$ \\
\hline \multicolumn{5}{|c|}{ Age (years) } \\
\hline $27-36$ & $2(3.1)$ & $11(21.6)$ & 13(11.2) & $6.7,18.2$ \\
\hline $37-46$ & 10(15.4) & $7(13.7)$ & $17(14.7)$ & $9.4,22.2$ \\
\hline $47-56$ & $17(26.2)$ & $14(27.4)$ & $31(26.7)$ & $19.5,35.4$ \\
\hline $57-66$ & $19(29.2)$ & $14(27.4)$ & $33(28.4)$ & $21 \cdot 0,37.3$ \\
\hline $67-76$ & $17(26.2)$ & $5(9.8)$ & $22(19.0)$ & $12.9,27.1$ \\
\hline \multicolumn{5}{|l|}{ Education } \\
\hline Informal & $1(1.5)$ & $2(3.9)$ & $3(2.6)$ & $0.9,7.3$ \\
\hline Primary & $21(32.3)$ & 17(33.3) & $38(32.8)$ & $24.9,41.7$ \\
\hline Secondary & 19(29.2) & 15(29.4) & $34(29.3)$ & $21.8,38.2$ \\
\hline Tertiary & 24(36.9) & 17(33.3) & $41(35.3)$ & $27.2,44.4$ \\
\hline \multicolumn{5}{|c|}{ Main occupation of respondent } \\
\hline Livestock & $44(67.7)$ & $38(74.5)$ & $82(70.7)$ & $61.9,78.2$ \\
\hline Others & $21(32.3)$ & $13(25.5)$ & $34(29.3)$ & $21.8,38.2$ \\
\hline \multicolumn{5}{|c|}{ Experience in livestock rearing (years) } \\
\hline$\leq 6$ & $31(47.7)$ & $13(25.5)$ & $44(37.9)$ & $29.6,47.0$ \\
\hline$>6$ & $34(52.3)$ & $38(74.5)$ & $72(62.1))$ & $52.9,70.4$ \\
\hline
\end{tabular}

neighbours of whom $3.1 \%$ were dairy cattle farmers and $3.9 \%$ poultry farmers. Across all the farmer categories, the primary purpose of antimicrobial use was for treatment $83.6 \%$ (95\%CI, 75.8, 89.3) followed by "treatment and prophylaxis" $13.8 \%$ (95\%CI, 8.6, 21.2), prophylaxis $1.7 \%(95 \% \mathrm{CI}, 0.5,6.1)$ and growth promotion $0.9 \%$ (95\%CI, 0.2, 4.7). About $89.2 \%$ of the small-scale dairy farmers indicated that treatment was their primary purpose for antimicrobial, compared with $76.5 \%$ of the poultry farmers.

When asked where they purchased antimicrobials used on cattle and poultry, $44 \%(95 \% \mathrm{CI}, 35.3,53.1)$ of the farmers said veterinary drug shops, $16.4 \%$ (95\%CI, 10.7, 24.2 ) veterinary clinics while $39.7 \%$ patronized individual veterinarians $(95 \% \mathrm{CI}, 31.2,48.8)$. Notable, $43.1 \%$ of the dairy cattle farmers indicated veterinary drug shops while $45.1 \%$ of the poultry farmers indicated so. $90.5 \%$ (95\% CI, $83.8,94.6)$ of the farms signaled that they engaged services of veterinarians/animal health, especially the dairy cattle farmers $(90.8 \%)$ while $9.5 \%(95 \%$ CI $5.4,16.2)$ of the farmers practiced self- administration.

In all the dairy farms visited, antimicrobials were administered through parenteral route while in $98 \%$ of the poultry farm orally via drinking water and $2 \%$ in feeds. Majority (65.7\%) were non-compliant to withdrawal periods, of whom, $63.1 \%$ were dairy cattle farmers and $66.7 \%$ were poultry farmers. Most farmers, $66.4 \%$ $(95 \% \mathrm{CI}, 57.4,74.3)$ stored their antimicrobials in cupboards, followed by open shelf indoors, $24.1 \%$ (95\%CI, 17.3, 32.7) and shelf direct sunlight, 9.5\% (95\%CI 6.4, 16.2), with some variations in the different farmer groups (Table 2).

Overall, $58.6 \%$ of the livestock farmers had adequate level of practices (favorable) in accordance to good antimicrobial use based on their responses. Farmers in the age group 27-36years were four times more likely to have unfavorable antimicrobial use practices than those in the age group $67-76$ years $(\mathrm{OR}=3.88 ; 95 \% \mathrm{CI}=1.71-6.05$; $p=0.001)$. Meanwhile, farmers with low educational qualifications (Primary school qualifications and below) were three times more likely to have unfavorable antimicrobial use practices than those with tertiary education $(\mathrm{OR}=2.71 ; 95 \% \mathrm{CI}=1.44-3.98 ; p=0.001)$ (Table 3$)$.

\section{Antimicrobials frequently used in poultry and cattle production}

A total of 17 antimicrobials were used among the poultry farms, which comprised of 7 classes (Additional file 2, Table $1 \& 2$ ). The most frequently used antimicrobials in poultry production were: enrofloxacin $25.5 \%$ ), followed by sulphonamides $(21.6 \%)$, oxytetracycline $(11.8 \%)$, tylo$\sin (11.8 \%) 195$ and flumequine (9.8) (Fig. 2).

In the small-scale dairy farms, 13 different types of antimicrobials comprising 7 classes were used (Additional file 2 , Table $3 \& 4$ ). The frequently used antimicrobials were oxytetracycline $(20.0 \%)$, followed by penicillin (18.5\%), sulphonamides (12.3\%), tylosin (12.3\%), penstrep (10.8\%), gentamicin (10.8\%), enrofloxacin, 5(7.7\%); ampicillin (4.6\%) and neomycin (3.1\%) (Fig. 2).

\section{Quantitative antimicrobial use}

This is different from the former, in that it deals with the amount of antimicrobials used. The DDD and UDD in both the poultry and cattle farms were determined based on the information in Additional file 1, (Table 2 \& 4) and also statistical data summary on the antimicrobials recalled, Table 5 in the same file. In the poultry farms with antimicrobial use records, sulfamethoxypyridazine (46.1\%) was the most frequently used antimicrobial agent, followed by oxytetracycline (19\%), tylosin (14.2\%) and enrofloxacin (11\%) while those farms which relied on recall, sulfamethoxypyridazine (28.8\%) was still the most frequently used antimicrobial agent, followed by oxytetracycline (18.5\%), tylosin (13.9\%) and enrofloxacin $(9.6 \%)$ (Table 4$)$. In the small-scale dairy farms with antimicrobial use records, penicillin (36.4\%) was the most frequently used antimicrobial agent, followed by 
Table 2 Practices of antimicrobial usage in livestock production by Farmers in Dar es Salaam, Tanzania

\begin{tabular}{|c|c|c|c|c|}
\hline \multirow[t]{2}{*}{ Practice } & \multicolumn{3}{|c|}{ Producer categories, $\mathrm{n}(\%)$} & \multirow[b]{2}{*}{$\begin{array}{l}\text { Confidence } \\
\text { interval } \\
(95 \%)\end{array}$} \\
\hline & Cattle (65) & Poultry (51) & Overall (116) & \\
\hline \multicolumn{5}{|c|}{ Source of drug information to the farmer } \\
\hline Veterinarian & $54(83.1)$ & $42(82.4)$ & $96(82.8)$ & $74.9,88.6$ \\
\hline Household experience & $9(13.8)$ & $7(13.7)$ & 16(13.8) & $8.7,21.2$ \\
\hline Neighbours & $2(3.1)$ & $2(3.9)$ & $4(3.5)$ & $1.4,8.5$ \\
\hline \multicolumn{5}{|l|}{ Purchasing place for antimicrobials } \\
\hline Veterinary drug shops & $28(43.1)$ & 23(45.1) & $51(44.0)$ & $35.3,53.1$ \\
\hline Veterinary clinic & 13(20.0) & $6(11.8)$ & 19(16.4) & $10.7,24.2$ \\
\hline Individual veterinarian & 24(36.9) & $22(43.1)$ & $46(39.7)$ & $31.2,48.8$ \\
\hline \multicolumn{5}{|l|}{ Purpose for antimicrobial usage } \\
\hline Therapeutic & $58(89.2)$ & $39(76.5)$ & 97(83.6) & $75.8,89.3$ \\
\hline Prophylaxis & $1(1.5)$ & $1(1.9)$ & $2(1.7)$ & $0.5,6.1$ \\
\hline Therapeutic \& Prophylaxis & $6(9.2)$ & 10(19.6) & 16(13.8) & $8.7,21.2$ \\
\hline Growth promotion & $0(0.0)$ & $1(1.9)$ & $1(0.9)$ & $0.2,4.7$ \\
\hline \multicolumn{5}{|l|}{ Drug sellers asking for prescriptions } \\
\hline Yes & $3(4.6)$ & 2(3.9) & $5(4.3)$ & $1.9,9.7$ \\
\hline No & $58(89.2)$ & $45(88.2)$ & 103(88.8) & $81.8,93.3$ \\
\hline Sometimes & $4(6.2)$ & $4(7.8)$ & $8(6.9)$ & $3.5,13.0$ \\
\hline \multicolumn{5}{|l|}{ Administration of drug to livestock } \\
\hline Veterinarian/Animal health worker & 59(90.8) & $46(90.2)$ & 105(90.5) & $83.8,94.6$ \\
\hline Self & $6(9.2)$ & $5(9.8)$ & $11(9.5)$ & $5.4,16.2$ \\
\hline \multicolumn{5}{|c|}{ Route of antimicrobial administration } \\
\hline Parenteral (Injection) & $65(100)$ & $0(0.0)$ & $65(56.0)$ & $46.9,64.7$ \\
\hline Water & $0(0.0)$ & $50(98.0)$ & $50(43.1)$ & $34.5,52.2$ \\
\hline Feeds & $0(0.0)$ & $1(2.0)$ & $1(0.9)$ & $0.2,4.7$ \\
\hline \multicolumn{5}{|c|}{ Compliance with drug withdrawal period } \\
\hline Yes & 24(36.9) & 17(33.3) & $41(35.3)$ & $27.2,44.4$ \\
\hline No & $41(63.1)$ & $34(66.7)$ & $75(64.7)$ & $55.6,72.8$ \\
\hline \multicolumn{5}{|l|}{ Antimicrobial storage } \\
\hline Cupboard & $43(66.2)$ & $34(66.7)$ & 77 & $57.4,74.3$ \\
\hline Open shelf indoor & $16(24.6)$ & $12(23.5)$ & 28 & $17.3,32.7$ \\
\hline Shelf direct sunlight & $6(9.2)$ & $5(9.8)$ & 11 & $5.4,16.2$ \\
\hline
\end{tabular}

sulfamethoxazole $(22.3 \%)$, oxytetracycline $(14.3 \%)$ and dihydrostreptomycin (11.5\%) while those which relied on recall, pencillin $(43.1 \%)$ still was the most frequently used antimicrobial agent, followed by dihydrostreptomycin (16.4\%), sulfamethoxazole (8.9\%) and gentamicin (6.8\%) (Table 5).

The averagely applied dosages to poultry and smallscale dairy farms, described as Defined Daily Dose (DDD) and Used Daily Dose (UDD) are presented above in Tables 4 and 5, respectively. From the ratio UDD to DDD it can be seen that in the poultry farms irrespective of antimicrobial use records or recall, all antimicrobials were over dosed, the same to the small-scale dairy farms with records. For those farms which relied on recall of antimicrobials in the small scale dairy farms, the ratio of UDD to DDD indicated that sulfadimidine, oxytetracycline and neomycin were appropriately dosed within the dosing range $(0.8-1.2)$ while the rest of antimicrobials were overdosed refer to Table 5 .

\section{Discussion}

This study revealed that antimicrobial use was a common practice among the poultry and cattle farmers and its use was $100 \%$ in both enterprises. Most of the antimicrobials were for treatment purposes and were mainly obtained from the veterinary drug shops. Both poultry and cattle 
Table 3 Socio-demographic characteristics of cattle and poultry farmers associated with antimicrobial use practices in Dar es Salaam

\begin{tabular}{|c|c|c|c|c|c|}
\hline Variable & $\begin{array}{l}\text { Number of respondents } \\
n(\%)\end{array}$ & $\begin{array}{l}\text { Unfavorable practices, } \mathrm{n} \\
\text { (row \%) }\end{array}$ & Odds ratio (OR) & 95\%Confidence Interval & P-value \\
\hline \multicolumn{6}{|c|}{ Age(in years) } \\
\hline $27-36$ & 13(11.2) & $10(76.9)$ & 3.88 & $1.71,6.05$ & 0.001 \\
\hline $37-46$ & $17(14.7)$ & $11(64.7)$ & 2.60 & $0.85,4.36$ & 0.004 \\
\hline $47-56$ & $31(26.7)$ & $13(41.9)$ & 1.19 & $-0.33,2.73$ & 0.124 \\
\hline $57-66$ & $33(28.4)$ & $10(30.3)$ & 0.33 & $-1.23,1.89$ & 0.678 \\
\hline $67-76$ & $22(19.0)$ & $4(18.2)$ & 1.00 & & \\
\hline \multicolumn{6}{|c|}{ Farmers' level of Education (Educ2) } \\
\hline Primary & $41(35.3)$ & $10(24.4)$ & 1.00 & & \\
\hline Secondary & $34(29.3)$ & $9(26.5)$ & 0.23 & $-1.03,1.49$ & 0.716 \\
\hline Tertiary & $41(35.3)$ & $29(70.7)$ & 2.71 & $1.44,3.98$ & 0.001 \\
\hline
\end{tabular}

Statistically significant at $p<0.05$

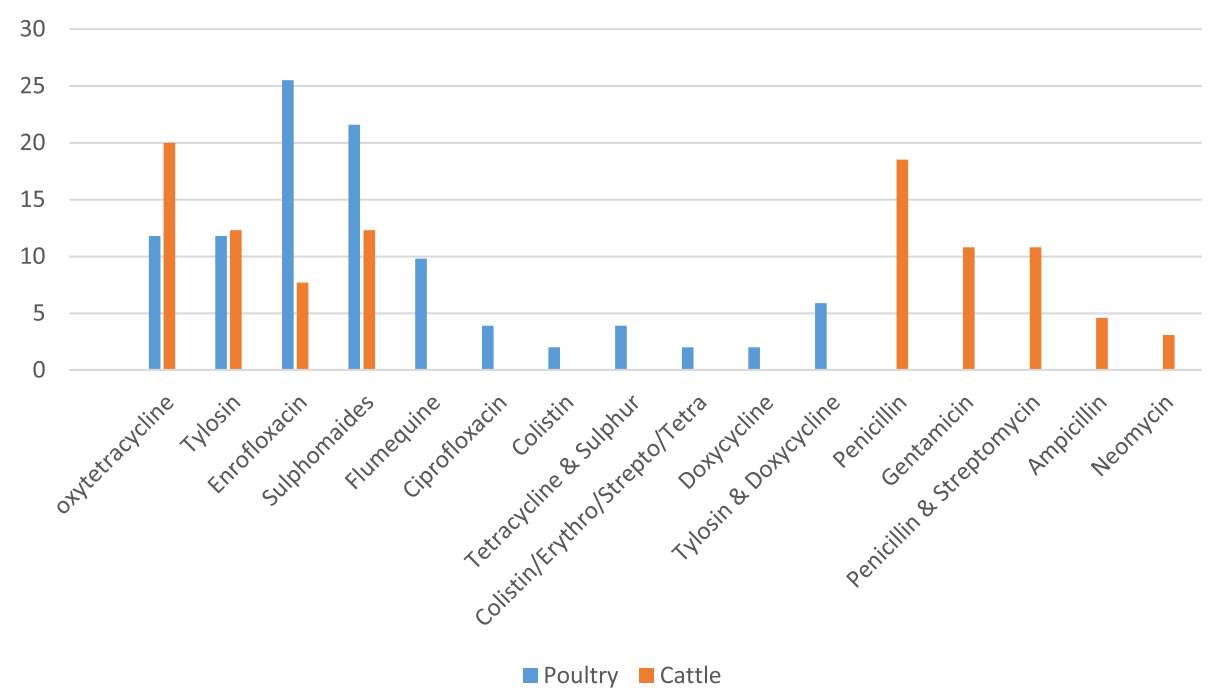

Fig. 2 Antimicrobials commonly used by poultry and cattle farmers in Dar-es-Salaam, Tanzania

farmers obtained their antimicrobial use information from the veterinarians. We found out that most farmers were not compliant with drug withdrawal periods. A variety of antimicrobials were used in the farms in the study area and the commonly used were tetracyclines, sulphonamides, fluoroquinolones macrolides, penicillin, penstrep and gentamicin. The study also found out that most of the antimicrobials were overdosed irrespective of the farmers having records or relied on recall while sulfadimidine, oxtetracycline and neomycin, were within the dosing range in cattle farms for those that relied on recall.

In poultry, in addition to therapeutic and /or prophylactic purposes, antimicrobial agents were used as growth promoters to a less extent. This finding is consistent with an earlier work done in Tanzania, [10] and elsewhere in Africa [12-14] but at variance with a study done in Ibadan, Nigeria by Olatoye [15] who reported that $86 \%$ of the poultry farms used antimicrobials for growth promotion. The small-scale nature of the investigated farms could probably hinder farmers from being financially buoyant to afford antimicrobials to be added to chicken feeds as growth promoters' continuously.

Regarding small-scale dairy farms, a high antimicrobial use was either for therapeutic and/ or prophylactic purposes or both. This is in agreement with the findings by other workers $[3,16,17]$. These uses have improved animal health, sustained productivity and reduced food borne pathogens [18]. However, regular use of these antimicrobial agents by the small-scale dairy farmers may result in the diminishing efficacy of the drugs due to development of bacterial resistance, [19]. It is worth noting that, the results in this study showed that the majority 
Table 4 Daily dosages $(\mathrm{mg} / \mathrm{kg})$, dosing ratios and total amount of antimicrobials used $(\mathrm{g})$ in surveyed poultry farms with records and those that relied on recall in Dar es Salaam, Tanzania

\begin{tabular}{|c|c|c|c|c|c|}
\hline Antimicrobial class & Antimicrobial name & DDD & UDD & UDD/DDD & Total used [g (\%)] \\
\hline \multicolumn{6}{|c|}{ Antimicrobials from farms with records } \\
\hline Diaminopyrimidines & Trimethoprim & 5.0 & 18.6 & 3.7 & $774.6(9.0)$ \\
\hline Fluoroquinolones & Enrofloxacin & 20.3 & 60.8 & 2.9 & $919.4(11.0)$ \\
\hline Macrolides & Tylosin & 9.5 & 32.4 & 3.4 & $1184.7(14.2)$ \\
\hline Polymyxins & Colistin & 5.3 & 15.8 & 2.9 & $23.7(0.3)$ \\
\hline \multirow[t]{2}{*}{ Sulphonamides } & Sulfadiazine & 11.3 & 33.8 & 2.9 & $33.8(0.4)$ \\
\hline & Sulfamethoxypyridazine & 28.1 & 112.5 & 4.0 & $3839.2(46.1)$ \\
\hline Tetracyclines & Oxytetracycline & 45.0 & 135.0 & 3.0 & $1552.6(19.0)$ \\
\hline \multicolumn{6}{|c|}{ Antimicrobials from farms which relied on recall } \\
\hline Aminoglycosides & Streptomycin & 7.9 & 23.6 & 2.9 & $9.5(0.4)$ \\
\hline Diaminopyrimidines & Trimethoprim & 8.8 & 26.4 & 3.0 & $149.2(6.4)$ \\
\hline \multirow[t]{3}{*}{ Fluoroquinolones } & Ciprofloxacin & 13.5 & 40.5 & 3.0 & $32.4(1.4)$ \\
\hline & Enrofloxacin & 18.3 & 56.2 & 3.1 & $223.5(9.6)$ \\
\hline & Flumequine & 21.0 & 63.0 & 3.0 & $156.6(6.7)$ \\
\hline \multirow[t]{2}{*}{ Macrolides } & Erythromycin & 7.9 & 23.6 & 2.9 & $9.5(0.4)$ \\
\hline & Tylosin & 14.1 & 43.3 & 3.1 & $324.9(13.9)$ \\
\hline Polymyxins & Colistin & 2.5 & 7.4 & 2.9 & $3.0(0.1)$ \\
\hline \multirow[t]{4}{*}{ Sulphonamides } & Sulfadiazine & 26.7 & 80.1 & 3.0 & $95.9(4.1)$ \\
\hline & Sulfadimerazine & 22.5 & 67.5 & 3.0 & $13.5(0.6)$ \\
\hline & Sulfadimidine & 33.3 & 99.9 & 3.0 & $137.8(5.9)$ \\
\hline & Sulfamethoxypyridazine & 42.2 & 127.1 & 3.0 & $671.6(28.8)$ \\
\hline \multirow[t]{2}{*}{ Tetracycline } & Oxytetracycline & 26.5 & 79.6 & 3.0 & $431.9(18.5)$ \\
\hline & Doxycycline & 18.6 & 55.7 & 2.9 & $71.6(3.1)$ \\
\hline
\end{tabular}

Defined Daily Dose (DDD), Used Daily Dose (UDD), Total used = Total volumes of antimicrobial used (grams)

of the farmers used antimicrobials for therapeutic purposes. This concurs with the study done in Peru [20].

Concerning our observation on antimicrobial usage among the farmers we visited in Dar es Salaam, although most of them are educated, a larger percentage were small scale farmers and thus in addition to sustenance of production, dependence on antimicrobials was probably due to lack of biosecurity, unhygienic practices and poor environmental sanitation which use may facilitate the emergence and spread of antibiotic-resistant pathogens [21].

We observed variations in the choice of antimicrobial agents used on the poultry and small-scale dairy farms in the study areas. This probably reflects the numerous numbers of manufacturers involved in antimicrobial production for veterinary use and thus farmers have opportunities to make choices on antimicrobial agents at will. In poultry, in both categories (those with records and those who relied on recall) fluoroquinolones, tetracyclines, sulphonamides and macrolides while in cattle (those with records and recall), tetracyclines, penicillin, sulphonamides and macrolides were the most dominantly used classes of antimicrobials. This concurs with previous studies in Tanzania $[3,6,10]$ and elsewhere in
Africa $[22,23]$ which revealed that these antimicrobials are commonly used in livestock production.

Quantitatively in poultry, the most commonly used antimicrobial class was sulphonamides followed by, tetracyclines, macrolides and fluoroquinolones. This is in agreement with the work done in Cameroon by [21]. While in the dairy, Beta-lactam/penicillin, sulphonamides, aminoglycosides and tetracycline were the most dominantly used classes of antimicrobials. This was in agreement with the work done in Nigeria and Peru [20, $23,24]$ whereby the frequently used antimicrobial classes were tetracycline (oxytetracycline), followed by betalactam/aminoglycoside (penicillin with or without streptomycin) and trimethoprim-sulphonamides. Similarly, a previous study by [19] in Pennsylvania reported that tetracycline and penicillin were the most frequently used antibiotics in dairy cattle. A study by [6] in Kinondoni district, Tanzania also revealed that tetracycline and sulfadimidine were mostly used. In the dairy quantitatively, the most commonly used antimicrobials were sulphonamides followed by beta-lactamase, aminoglycosides, tetracyclines and macrolides. These antimicrobial agents are frequently used by poultry and dairy producers probably because they are easily acquired across the counter, 
Table 5 Daily dosages ( $\mathrm{mg} / \mathrm{kg}$ ), dosing ratios and total amount of antimicrobials used $(\mathrm{g})$ in surveyed small scale dairy farms with records and those that relied on recall in Dar es Salaam, Tanzania

\begin{tabular}{|c|c|c|c|c|c|}
\hline Antimicrobial class & Antimicrobial name & $\mathrm{DDD}(\mathrm{mg} / \mathrm{kg})$ & $\mathrm{UDD}(\mathrm{mg} / \mathrm{kg})$ & UDD/DDD & Total used [g (\%)] \\
\hline & \multicolumn{5}{|c|}{ Antimicrobials from farms with records } \\
\hline Beta-lactam & Penicillin & 16.0 & 47.5 & 2.9 & $404.0(36.4)$ \\
\hline \multirow[t]{2}{*}{ Aminoglycosides } & Dihydrostreptomycin & 10.0 & 30.0 & 3.0 & $127.5(11.5)$ \\
\hline & Gentamicin & 5.0 & 14.8 & 2.9 & $44.1(4.0)$ \\
\hline Diaminopyrimidines & Trimethoprim & 3.4 & 7.5 & 2.2 & $44.9(4.0)$ \\
\hline Fluoroquinolones & Enrofloxacin & 7.5 & 21.9 & 2.9 & $83.7(7.5)$ \\
\hline Sulphonamides & Sulfamethoxazole & 17.0 & 37.4 & 2.2 & $247.2(22.3)$ \\
\hline \multirow[t]{2}{*}{ Tetracycline } & Oxytetracycline & 10.0 & 15.8 & 1.6 & $159.0(14.3)$ \\
\hline & \multicolumn{5}{|c|}{ Antimicrobials from farms which relied on recall } \\
\hline \multirow[t]{2}{*}{ Beta-lactam } & Ampicillin & 11.1 & 30.6 & 2.8 & $174.0(4.2)$ \\
\hline & Penicillin & 16.0 & 34.3 & 2.1 & $1791.1(43.1)$ \\
\hline \multirow[t]{3}{*}{ Aminoglycosides } & Dihydrostreptomycin & 11.1 & 36.2 & 3.3 & $679.0(16.4)$ \\
\hline & Gentamicin & 5.0 & 14.2 & 2.8 & $282.0(6.8)$ \\
\hline & Neomycin & 20.0 & 24.7 & 1.2 & $150.0(3.6)$ \\
\hline Diaminopyrimidines & Trimethoprim & 2.6 & 5.4 & 2.1 & $91.7(2.2)$ \\
\hline Fluoroquinolones & Enrofloxacin & 5.6 & 10.6 & 1.8 & $235.2(5.7)$ \\
\hline \multirow[t]{3}{*}{ Sulphonamides } & Sulfadiazine & 12.5 & 35.3 & 2.8 & $90.0(2.2)$ \\
\hline & Sulfadimidine & 33.3 & 28.2 & 0.8 & $59.9(1.4)$ \\
\hline & Sulfamethoxazole & 13.1 & 25.1 & 1.9 & $368.4(8.9)$ \\
\hline Tetracycline & Oxytetracycline & 10.0 & 9.6 & 0.9 & $230.3(5.5)$ \\
\hline
\end{tabular}

Defined Daily Dose (DDD), Used Daily Dose (UDD), Total used = Total volumes 223 of antimicrobial used (grams)

relatively inexpensive, and cost-effective as when contrasted to third generation antimicrobial agents. Besides, almost all antimicrobials were overdosed in both poultry and dairy farms apart from sulfadimidine, oxytetracycline and neomycin which were within the dosing range (0.8-1.2) in small scale dairy farms. However, it should be noted that underdose of antimicrobial use has been linked to antimicrobial resistance emergence in food producing animals [25] as reported in Kenya by [26] in chicken meat.

Most of the antimicrobials encountered in the poultry and dairy farms visited in this study were either classified as critically or highly important for humans [27]. The antimicrobial formulation classified under critically important are (fluoroquinolones) or highly important (sulphonamides, tetracyclines). The use of fluoroquinolones in food producing animals is worrisome as it is effective in the treatment of human enteric infection. It has been reported that in farm animals where it is used, it is associated with increased resistance in human exposed to it [28]. Fluoroquinolone has gained increased use due to its broad-spectrum activity, oral preparation and potency and lack of restrictions among other factors. The use of banned substances such as colistin in China as a growth promoter is also of concern [29]. Colistin is very valuable to treat nosocomial infections caused by multidrugresistant gram-negative bacteria in humans [30].
As observed in the previous poultry studies in Sudan [31] and Nigeria [14] the present study showed that most farmers administered antimicrobials via drinking water and only one in feeds. In this regard whichever way is used [32] there is imprecise dosing whereby an animal can decide on the amount of either water or feed to be consumed which has effect on potentially increasing selection for resistance. In the dairy, the antimicrobials were administered through parenteral route. This is in agreement with studies done elsewhere in Africa [23]. This is probably due to the fact that most formulations are prepared to be applied through the parenteral routes.

Although the results in the present study indicate that the majority of poultry and dairy farmers complied with the services of qualified personnel for drug prescription, antimicrobial use in Tanzania is still a problem. In poultry in the study done elsewhere in Africa [12, 22] antimicrobial prescription was done by qualified personnel. We found out that a quarter of the farms practiced self-medication and a third did not comply with the antimicrobial withdrawal periods. This concurs with what $[22,33]$ reported in studies in Cameroon that a small proportion of poultry farms surveyed did not rely on prescriptions by veterinarians and were also not compliant with antimicrobial withdrawal periods. Similarly in the dairy, a nonnegligible proportion of farms investigated did not rely on prescription by veterinarians and did not comply with 
withdrawal periods. This is consistent with the previous work done by [34] in Nigeria but contrary to the results reported in Boston by [35] where in addition to reliance on veterinary antimicrobial use recommendations, dosage and withdrawal periods were observed among cattle farmers. All in all, both in poultry and dairy farming selfadministration may be linked to improper antimicrobial use and noncompliance to withdrawal durations to high concentrations of antimicrobials in animal products. In Tanzania this could be attributed to lack of enforcement of legislations concerning antimicrobial application to farm animals in Tanzania [10].

This study has revealed that the majority of respondents had adequate level of antimicrobial usage practices in poultry and cattle production. This may be explained by the fact that these farmers are located within the urban areas where they have access to veterinary guidance and advisory services.

We found socio-demographic characteristics of age and education to have influence on unfavorable practices of antimicrobial usage. This is likely to result into misuse of antimicrobials and hence emergence of antimicrobial resistance. Health education of the farmers through mass media like radio is imperative for behavior modification and social change towards proper antimicrobial usage practices [24].

Understanding antimicrobial use pattern currently in cattle and poultry production is of importance in developing mitigation options for judicious antimicrobial usage, which may potentially reduce antimicrobial resistance (AMR) risks in animal production [36].

In general, practices related to non-prudent antimicrobial usage were noted in this study and this may imply increased emergence of antimicrobial-resistant bacteria from farm animals to humans through various pathways. Therefore trainings and awareness increase campaigns on antimicrobials, their usage and resistance should be promoted among the livestock officers/ veterinarians. This is because we documented non-prudent AMU practices and secondly veterinarians/livestock officers are involved in antimicrobial administration. We also noted that those farmers who self-administered drugs did not have antimicrobial use records and thus need of awareness campaigns. This will help the participants to mitigate non prudent use and thus decrease the spread of resistance.

This study has some limitations. Even though the questionnaire used as data collection tool was pre-tested to ensure quality control, data was captured over a short period from respondents. This implies that the collected data can misrepresent true dispositions and recall bias especially for those farmers who are not administering their antimicrobials and also those who lack records completely.
Since most of the respondents relied on self-recall this may have affected the findings of the study. Self-recall can be affected by reporting and social desirability bias [20]. A better method of AMU data collection could be use of bins since they represent a convenient and fairly accurate ways of recording antimicrobial drug use [37] at regular intervals over a long period of time.

\section{Conclusion}

The present study has revealed that, majority of the respondents had adequate level (58.6\%) of antimicrobial use practices and few moderate level $(41.4 \%)$. This could probably be associated with availability of veterinary services. Self-administration and non-compliance to antimicrobial withdrawal periods, has a public health implication as it may result in medication failure, AMR development and occurrence of drug residues in food animal products like meat, milk or eggs. Secondly the study provides a basis for development and enforcement of policies on antimicrobial use in food producing animals with a view to safeguard public health. Although it is not possible for the data in this study to be extrapolated to other parts of Tanzania, the data collection instrument can easily be used elsewhere.

\section{Methods \\ Study design}

A cross-sectional study design was used to solicit information on antimicrobial use from poultry and small scale dairy production farmers.

\section{Study area and target population}

The study was conducted from 15th August to 30th September 2019 in three districts of Dar es Salaam city, Eastern Tanzania which were purposively selected. It covered nine wards (administrative units), namely Kipawa and Kipungu in Ilala district, Bunju, Kijitonyama, Kunduchi and Wazo in Kinondoni district and Goba, Mbezi and Saranga in Ubungo district as shown in Fig. 3. These areas were selected based on their relatively high livestock activities; species of interest found and unregulated access to veterinary drugs.The target populations were farmers with poultry and small-scale dairy farms, aged 18 years and above, with a population of 100 or more birds and those with 2 or more dairy cattle.

\section{Farm selection}

Farm selection combined random and purposive sampling based on its location. A list of 212 poultry and Small-scale dairy farms in the study districts, from which 146 farms were initially selected randomly for this survey, was provided by the District Veterinary Officers. In instances where farms were inaccessible due to distance 


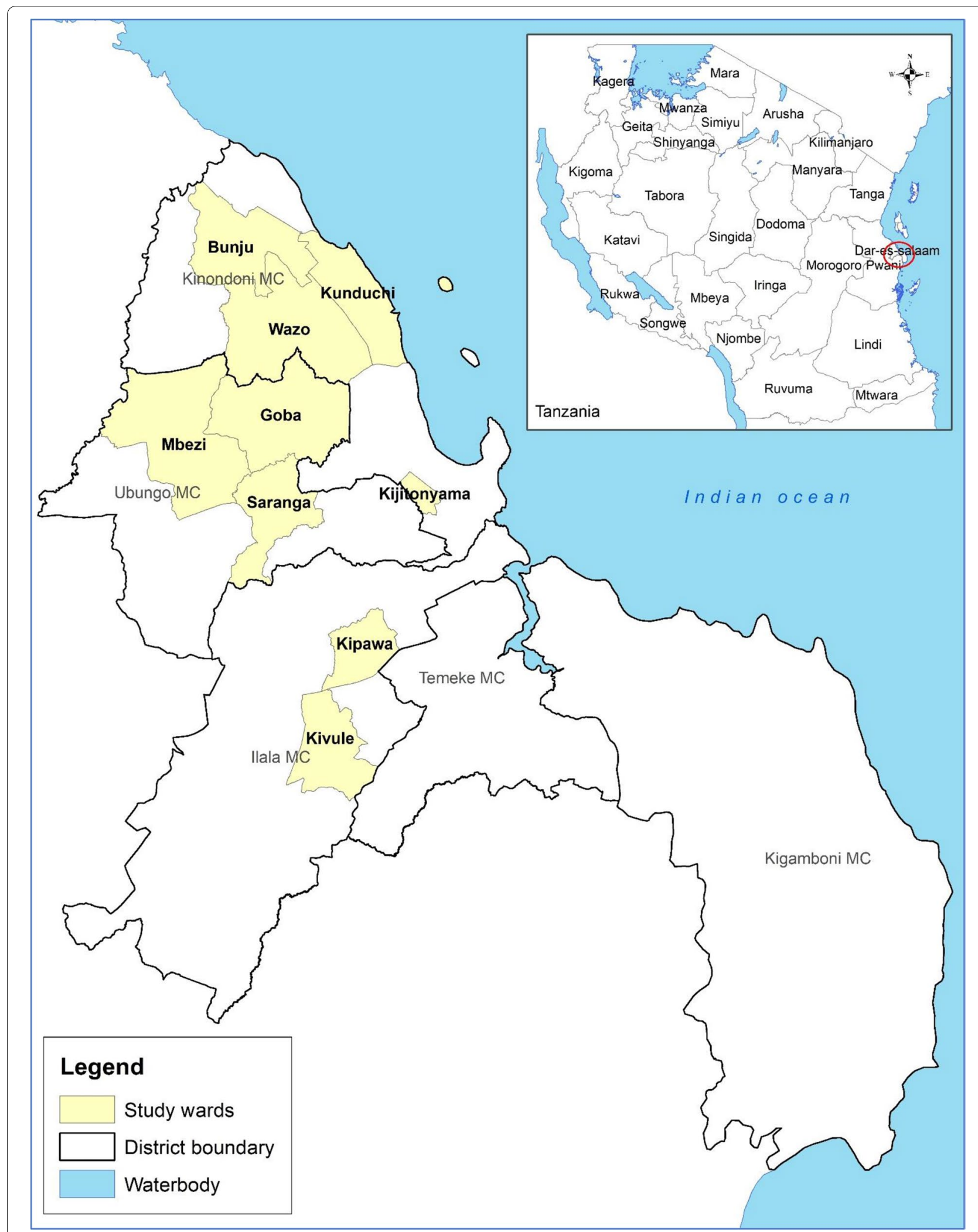

Fig. 3 Map of the study districts (wards) in Dar- es- Salaam, Tanzania 
or unwillingness of farmers to participate, they were substituted with others. Eventually, 116 farms were sampled. This is because some of the farms were not accessible after several attempts, other farmers refused to participate due to lack of feedback and benefits in earlier studies where they were involved. Of these farms, 65 (56\%) were small-scale dairy farms while $51(44 \%)$ were poultry farms.

\section{Data collection}

A structured questionnaire (Additional file 3) designed in English and digitalized into AfyaData, a mobile digital data application [38] was installed on a smartphone, pre-tested to minimise variations and improve its consistency to responses [39]. At the time of administration, it was translated in Kiswahili to farmers who did not know English in person on their farms? It included both closed \& open-ended questions. The questionnaire consisted of three main sections: i) farmers sociodemographic characteristics ii) Cattle and iii) Poultry sections; farm attendants/owners were expected to give detailed information on numerous antimicrobial agents used in the past 5 months (in conjunction with the farmers' treatment records and those of the livestock officer in charge) including: Route of application, purpose of use, drug withdrawal duration and vicinity of purchase. Other information obtained were product commercial name (which was classified by its active substance), livestock number, number of animals treated in the previous 5 months, type of antimicrobials used in the treatment doses, frequency of use, and number of days of treatment using recall or treatment records if at all they were available. The number of farms with antimicrobial use records and those which relied on recall use were noted. The obtained information was used to quantify the active Ingredients. To minimise recall bias, visual aid photos on the packages and labels for most antimicrobials used in livestock treatment were used.

\section{Data management and statistical analysis}

Data from the questionnaires were downloaded into Microsoft Excel $^{\circledR}$ 2007, cleaned, summarized and exported to IBM SPSS Statistics for windows, Version 2010 for further analysis. Descriptive statistics for all variables in the forms of frequencies and proportions were calculated. To determine the farmers level of antimicrobial use practices, each validated question was independently analysed and assigned a score. A desirable answer received a score of 'one' and undesirable 'zero' (Additional file 4).To analyse how each individual farmer Performed in the antimicrobial use practices, the sum of scores for each farmer was calculated which ranged between 0 and 12 where 0 is for a farmer who would score ' 0 ' for each question and 12 for a farmer who would score ' 1 ' for each question. From the sum of scores for each farmer a median score of seven (7) was computed and this was used as a cutoff point, such that any score $<7$ was considered to be "Unfavorable" and $\geq 7$ "Favorable". Statistical associations were determined by Chi-square test and binary logistic regression analysis (BLRA) between categories whereby those with favorable practices constituted $58.6 \%$ and the rest unfavorable practices. The impact of farmers' socio demographic profiles or association with respect to practices of antimicrobial agent usage was determined by binary logistic regression analysis. In order to be considered statistically significant, BLRA had to have a probability cut-off of 0.05 . Odds ratios were calculated and then the $95 \% \mathrm{CI}$ for the strength of association between variables was determined.

Antimicrobial use quantification was based on dose metrics. The quantity of active ingredient (milligrams) in each antimicrobial class were determined as follows: Active ingredients $(\mathrm{mg})=$ no. of animals treated in the study period $\mathrm{x}$ antimicrobial drug concentration $(\mathrm{mg} /$ $\mathrm{ml}) \mathrm{x}$ units per treatment $(\mathrm{ml}) \mathrm{x}$ treatments per day $\mathrm{x}$ number of treatment days (for cattle) while for poultry was based on the quantity of drug consumed in water or feed multiplied by antimicrobial drug concentration $(\mathrm{mg} / \mathrm{ml})$. The daily water intake of $1 \mathrm{~kg}$ live chicken at ambient temperature of $320 \mathrm{C}$ is $225 \mathrm{ml}$ [40] while the daily feed consumption from Published data on a native Vietnamese layer is $63.4 \mathrm{~g}$ per kilogram of live chicken [41].Conversion factors for prodrugs (such as procaine benzyl penicillin) and international units (I.U.) were obtained from the ESVAC protocol [42]. The indiactors used were Defined Daily Dose (DDDvet mg/ $\mathrm{kg}$ ) and Used Daily Dose (UDDvet $\mathrm{mg} / \mathrm{kg}$ ) [43] which were calculated based on the farms' antimicrobial use records or recall. A two group t-test was used to determine whether a significance difference existed between those who had records and those who relied on recall. The defined daily dose (DDD) as defined previously [44] as the average maintenance dose per day and per $\mathrm{kg}$ chicken/cattle of a specific drug, is determined on the basis of the instructions on drug's leaflet. In case a single dose was indicated on the label, that was the DDDvet $(\mathrm{mg} / \mathrm{kg})$ and if a range of doses, the mean is the DDDvet. (mg/kg) [43]. For combined antimicrobials, the DDDvet value for each active ingredient was determined [45]. The standard weights considered for the study are those proposed by ESVAC [45].

The used daily dose (UDD), which defines a standard treated livestock/ animal [46] was determined by taking the average of the total amount of the administered 
antimicrobial compound in milligrams (mgs) and the number of animals times the mean weight at treatment. The ratio of UDD to DDD assesses the appropriateness of dosage as based on the investigation by Grave et al. [47]. Ratios within the range of 0.8 and 1.2 are considered as appropriate dosing while any value below 0.8 and above 1.2 are considered as under dosed and overdosed, respectively.

\begin{abstract}
Abbreviations
AMU: Antimicrobial use; AMR: Antimicrobial resistance; BLRA: Binary logistic regression analysis; Cls: Confidence Intervals; DDD: Defined Daily Dose; ESVAC: European Surveillance of Veterinary Antimicrobial Consumption; g: grams; I.U: International Unit; mg: milligrams; mg/kg: milligram/kilogram; mg/ml: milligram/milliliter; ml: milliliter; n: number; OR: Odds Ratio; $P$-value: Probabilityvalue; \%: Percentage; UDD: Used Daily Dose.
\end{abstract}

\section{Supplementary Information}

The online version contains supplementary material available at https://doi. org/10.1186/s12917-021-03056-9.

\section{Additional file 1.}

Additional file 2 .

Additional file 3.

Additional file 4 .

\section{Acknowledgements}

The authors wish to thank the Government of the United Republic of Tanzania and World Bank through SACIDS Foundation for One Health for providing a scholarship grant to R.A. We also extend our sincere thanks to the district authorities where data was collected and colleagues in Antimicrobial Community of Practice (COP) at the SACIDS Foundation for One Health for their continuous encouragement during the study. The poultry and small scale dairy farmers who participated in the study.

\section{Authors' contributions}

RA, MS, MM, and SIK were all involved in the design of the study; RA collected data. RA and SIK analysed the data. RA drafted the manuscript. SIK and MM coordinated and supervised the study. MM, SIK, and MS, revised the manuscript; and all authors approved the final manuscript.

\section{Funding}

Government of Tanzania and World Bank through SACIDS Foundation for One Health, Sokoine University of Agriculture, Morogoro, Tanzania. The funders had no role in the design of the study and collection, analysis and interpretation of data and in writing the manuscript.

\section{Availability of data and materials}

The datasets used and/or analysed during the current study are available from the corresponding author on reasonable request.

\section{Declarations}

\section{Ethics approval and consent to participate}

Ethical approval was obtained from National Institute of Medical Research of Tanzania, (Ref \#.NIMR/HQ/R.8a/Nol.IX/3233). The ethics committee approved the procedure for thumbprinted consent, and why they felt the need for written consent was not necessary for this study. The objective of the study was explained to the farmers by the researcher, the consent form read out to them, and those who agreed either appended their signatures or thumbprints on the form before the interview. Confidentiality of the farmers was kept using unique codes.
Consent for publication

Not applicable.

\section{Competing interests}

The authors declare that they have no competing interests.

\section{Author details}

'Department of Veterinary Microbiology, Parasitology and Biotechnology, College of Veterinary Medicine and Biomedical Sciences, Sokoine University of Agriculture, Morogoro, Tanzania. ${ }^{2}$ National Livestock Resources Research Institute, Kampala, Uganda. ${ }^{3}$ SACIDS Foundation for One Health Sokoine University of Agriculture, Morogoro, Tanzania. ${ }^{4}$ Department of Microbiology/ Immunology, Weill Bugando School of Medicine, Catholic University of Health and Allied Sciences, Bugando, Mwanza, Tanzania. ${ }^{5}$ Department of Microbiology and Immunology, School of Medicine, Muhimbili University of Health and Allied Sciences, Dar es Salaam, Tanzania. ${ }^{6}$ Department of Veterinary Medicine and Public Health, College of Veterinary Medicine and Biomedical Sciences, Sokoine University of Agriculture, Morogoro, Tanzania.

Received: 26 October 2020 Accepted: 20 October 2021

Published online: 03 January 2022

\section{References}

1. Prescott JF. Antimicrobial use in food and companion animals. Anim Health Res Rev. 2008;9:127-33.

2. Caudell MA, Quinlan MB, Subbiah M, Call DR, Roulette CJ, Roulette JW, et al. Antimicrobial use and veterinary care 498 among agro-pastoralists in northern Tanzania. PLoS One. 2017;12(1):1-18.

3. Karimuribo ED, Mdegela RH, Kusiluka LJM, Kambarage DM. Assessment of drug usage and antimicrobial residues in milk on smallholder farms in Morogoro, Tanzania. Bull Animal Health Prod Africa. 2005:53(4):234-41.

4. Kashoma IP, Kassem II, John J, Kessy BM, Gebreyes W, Kazwala RR, et al. Prevalence and antimicrobial resistance of Campylobacter isolated from dressed beef carcasses and raw milk in Tanzania. Microb Drug Resist. 2016:22(1):40-52.

5. Kimera ZI, Mdegela RH, Mhaiki CJN, Karimuribo ED, Mabiki F, Nonga HE, et al. Determination of oxytetracycline residues in cattle meat marketed in the Kilosa district, Tanzania. Onderstepoort J Vet Res. 2015;82(1):1-5.

6. Katakweba AAS, Mtambo MMA, Olsen JE, Muhairwe AP. Awareness of human health risks associated with the use of antimicrobials among livestock keepers and factors that contribute to selection of antibiotic resistance bacteria within livestock in Tanzania. Livestock Rural Res Dev. 2012;24(10):1-14

7. Van Boeckel TP, Brower C, Gilbert M, Grenfell BT, Levin SA, Robinson TP, et al. Global trends in antimicrobial use in food animals. Proc Natl Acad Sci U S A. 2015;112(18):5649-54

8. Mubito EP, Shahada F, Kimanya ME, Buza JJ. Antimicrobial use in the poultry industry in Dar-es-salaam, Tanzania and public health implications. American J Res Com. 2014;2(4):51-63.

9. Nonga HE, Muhairwa AP. Prevalence and antibiotic susceptibility of thermophilic Campylobacter isolates from free range domestic duck (Cairina moschata) in Morogoro municipality, Tanzania. Trop Anim Health Prod. 2010:42:165-72.

10. Nonga HE, Mariki M, Karimuribo ED, Mdegela RH. Assessment of antimicrobial usage and residues in broiler chickens in Morogoro municipality, Tanzania. Pakistan J Nutr. 2009;8(3):203-7.

11. Landers TF, Cohen B, Wittum TE, Larson EL. A review of antibiotic use in food animals: perspective, policy, and potential. Public Health Rep. 2012;127(1):4-22

12. Bashahun GMD, Odoch AT. Assessment of antibiotic usage in intensive poultry farms in Wakiso District, Uganda. Livest Res Rural Dev. 2015; 27(247).Available via http://www.lrrd.org/lrrd27/12/bash27247.html. Accessed 16 Feb 2016.

13. Oluwasile BB, Agbaje M, Ojo OE, Dipeolu MA. Antibiotic usage pattern in selected poultry farms in Ogun state. Sokoto Journal of Veterinary Sciences. 2014;12(1):45-50.

14. Awogbemi J, Adeyeye M, Akinkunmi EO. A survey of antimicrobial agents usage in poultry farms and antibiotic resistance in Escherichia Coli and 
staphylococci isolates from the poultry in Ile-Ife, Nigeria. J Infect Dis Epidemiol. 2018;4(1):1-9.

15. Olatoye IO. Antibiotics use and resistance patterns of Salmonella species in poultry from Ibadan. Nigeria Tropical Veterinarian. 2011;29(1):28-35.

16. Beyene T, Tesega B. Rational veterinary drug use: its significance in public health. Journal of Veterinary Medicine and Animal Health. 2014;6(12):302-8

17. Oliver SP, Murinda SE, Jayarao BM. Impact of antibiotic use in adult dairy cows on antimicrobial resistance of veterinary and human pathogens: a comprehensive review. Food borne Pathog Dis. 2011;8:337-55.

18. Mathew AG, Cissell R, Liamthong S. Antibiotic resistance in bacteria associated with food animals: a United States perspective of livestock production. Food borne Pathog Dis. 2007:4:115-33.

19. Sawant AA, Sordillo LM, Jayarao BM. A survey on antibiotic usage in dairy herds in Pennsylvania. J Dairy Sci. 2005;88(8):2991-9.

20. Redding LE, Cubas-Delgado F, Sammel MD, Smith G, Galligan DT, Levy $M Z$, et al. The use of antibiotics on small dairy farms in rural Peru. Prev Vet Med. 2014;113(1):88-95.

21. Graham JP, Price LB, Evans SL, GraczykTK, Silbergeld EK. Antibiotic-resistant enterococci staphylococci isolated from flies collected near confined poultry feeding operations. Sci Total Environ. 2009;407:2701-10.

22. Kamini MG, Keutchatang FT, Huguette YM, Kansci Germain A, Gabriel MN. Antimicrobial usage in the chicken farming in Yaoundé, Cameroon: a cross sectional study. Int J Food Contam. 2016;3(1):1-6.

23. Ogunleye AO, Oyekunle MA, Sonibare AO. Multi-drug resistant Escherichia coli isolates of poultry origin in Abeokuta, South Western Nigeria. Vet Arhiv. 2008;78(6):501-9.

24. Alhaji NB, Aliyu MB, Ghali-Mohammed I, Odetokun IA. Survey on antimicrobial usage in local dairy cows in North-central Nigeria: Drivers for misuse and public health threats. PLOS ONE. 2019;14 (12):1-14.

25. Marshall BM, Levy SB. Food animals and antimicrobials: impacts on human health. Clin Microbiol Rev. 2011;24(4):718-33.

26. Odwar JA, Kikuvi G, Kariuki JN, Kariuki S. A cross-sectional study on the microbiological quality and safety of raw chicken meats sold in Nairobi, Kenya. BMC Res Notes. 2014;7(627):1-8.

27. WHO. Critically important antimicrobials for human medicine, 3rd Revision 2011. 2012 World Health Organization, Geneva, Switzerland. Available via http://apps.who.int/iris/bitstream/10665/77376/1/9789241504 485_eng.pdf. Accessed 16 Feb 2016

28. Adebowale OO, Adeyemo OK, Awoyomi O, Dada R, Adebowale O. Antibiotic use and practices in commercial poultry laying hens in Ogun state Nigeria. Rev Elev Vet Pays Trop. 2016;69(1):41-5.

29. The review on antimicrobial resistance. Antimicrobials in agriculture and the environment: reducing unnecessary use and waste. London: Wellcome Trust; 2015. Available from: https://amr-review.org/sites/defau It/files/ Antimicrobials in agriculture and the environment - Reducing unnecessary use and waste.pdf [cited 2017 Oct 17].

30. Kadar B, Kocsis B, Nagy K, Szabo D. The renaissance of Polymyxins. Curr Med Chem. 2013;20:3759-73.

31. Sirdar MM, Picard J, Bisschop S, Gummow B. A questionnaire survey of poultry layer farmers in Khartoum state, Sudan, to study their antimicrobial awareness and usage patterns. Onderstepoort J Vet Res. 2012;79(1):1-8

32. Love DC, Davis MF, Bassett A, Gunther A, Nachman KE. Dose imprecision and resistance: free-choice medicated feeds in industrial food animal production in the United States. Environ Health Persp. 2011;119:279-83.

33. Guetiya Wadoum RE, Zambou NF, Anyangwe FF, Njimou JR, Coman MM, Verdenelli MC, et al. Abusive use of antibiotics in poultry farming in Cameroon and the public health implications. Br Poult Sci. 2016;57(4):483-93.

34. Mamza SA, Geidam YA, Gideon DM, Godwin OE. Antimicrobial Usage in Livestock Management in North-Eastern Nigeria: A Survey of Livestock Farmers. Int J Sci Res Methodol. 2017;8(2):149-72.

35. Zwald AG, Ruegg PL, Kaneene JB, Warnick LD, Wells SJ, Fossier C, et al. Management practices and reported antimicrobial usage on conventional and organic dairy farms. J Dairy Sci. 2004;87:191-201.

36. Lekagul A, Tangcharoensathien V, Yeung S. Patterns of antibiotic use in global pig production: a systematic review. Vet Anim Sci. 2019;7:100058.

37. Dunlop RH, McEwen SA, Meek AH, Black WD, Clarke RC, Friendship RM. Individual and group antimicrobial usage rates on 34 farrow-to-finish swine farms in Ontario, Canada. Prev Vet Med. 1998;34:247-64.
38. Karimuribo, E.D.; Mutagahywa, E.; Sindato, C.; Mboera, L.; Mwabukusi, M.; Kariuki, N.M. A Smartphone App (AfyaData) for Innovative One Health Disease Surveillance from Community to National Levels in Africa: Intervention in Disease Surveillance. JMIR Public Health Surveill. 2017, 3, e94. [CrossRef].

39. Thrusfield, M. Veterinary Epidemiology, 3rd ed, Blackwell Science Ltd, a Blackwell Publishing company, 9600 Garsington Road, Oxford OX4 2DQ, UK. 2009; 228-238.

40. Anon. Poultry Water Consumption. 2019. Available online at: https:// www.heatstress.info/heatstressinfo/Admin/WaterandFeedconsumptionin poultry/tabid/2135/Default.aspx (Accessed 28 Dec 2018).

41. Anon. High Yield Pullets and Adult Layers DeHeus. 2019. Available online at https://www.deheus.com.vn/san-pham/thuc-an-cho-ga/ga-de (Accessed 14 Jan 2019).

42. European Medicines Agency. Guidance on collection and provision of national data on antimicrobial use by animal species/categories. 2018 Available a https://www.ema.europa.eu/en/documents/scientific-guide line/guidance-collection-provisionnational-data-antimicrobial-use-anima Ispecies/categories_en.pdf(Accessed 20 Mar 2020).

43. Saini V, McClure JT, Leger D, Dufour S, Sheldon AG, Scholl DT, et al. Antimicrobial use on Canadian dairy farms. J Dairy Sci. 2012;95:1209-21.

44. Jensen VF, Jacobsen E, Bager F. Veterinary antimicrobial-usage statistics based on standardized measures of dosage. Prev Vet Med. 2004;64:201-15.

45. European Medicine Agency. Revised ESVAC Reflection Paper on Collecting Data on Consumption of Antimicrobial Agents per Animal Species, on Technical Units of Measurement and Indicators for Reporting Consumption of Antimicrobial Agents in Animals. 2013 EMA/286416/2012-Rev.1.

46. Timmerman T, Dewulf J, Catry B, Feyen B, Opsomer G, de Kruif A, et al. Quantification and evaluation of antimicrobial drug use in group treatments for fattening pigs in Belgium. Prev. Vet. Med. 2006;74:251-63.

47. Grave K, Greko C, Nilsson L, Odensvik K, Mørk T, Rønning M. The usage of veterinary antibacterial drugs for mastitis in cattle in Norway and Sweden during 1990-1997. Prev Vet Med. 1999;42:45-55.

\section{Publisher's Note}

Springer Nature remains neutral with regard to jurisdictional claims in published maps and institutional affiliations.

Ready to submit your research? Choose BMC and benefit from:

- fast, convenient online submission

- thorough peer review by experienced researchers in your field

- rapid publication on acceptance

- support for research data, including large and complex data types

- gold Open Access which fosters wider collaboration and increased citations

- maximum visibility for your research: over $100 \mathrm{M}$ website views per year

At BMC, research is always in progress.

Learn more biomedcentral.com/submissions 